\title{
Sorption of methylene blue on treated agricultural adsorbents: equilibrium and kinetic studies
}

\author{
D. P. Tiwari $\cdot$ S. K. Singh $\cdot$ Neetu Sharma
}

Received: 12 September 2013/Accepted: 25 February 2014/Published online: 23 March 2014

(C) The Author(s) 2014. This article is published with open access at Springerlink.com

\begin{abstract}
Agricultural adsorbents are reported to have a remarkable performance for adsorption of dyes. In the present study, formaldehyde and sulphuric acid treated two agricultural adsorbents; potato peel and neem bark are used to adsorb methylene blue. On the whole, the acid-treated adsorbents are investigated to have high sorption efficiency compared to $\mathrm{HCHO}$ treated adsorbents. The percentage removal efficiency of $\mathrm{H}_{2} \mathrm{SO}_{4}$ treated potato peel (APP) increases considerably high from 75 to $100 \%$ with increase in adsorbent dose, whereas the removal efficiency of $\mathrm{H}_{2} \mathrm{SO}_{4}$ treated neem bark (ANB) is found to be $98 \%$ after adding the first dose only. The monolayer sorption behaviour of HCHO treated potato peel (PP) and APP is well defined by Langmuir, whereas the chemisorptions behaviour of $\mathrm{HCHO}$ treated neem bark (NB) and ANB is suggested by Temkin's isotherm model. The maximum adsorption capacity measured is highest in ANB followed by NB, PP and APP with the values of 1000, 90, 47.62 and $40.0 \mathrm{mg} / \mathrm{g}$, respectively. The pseudo-second-order kinetic model fitted well with the observed data of all the four adsorbents. The results obtained reveal that NB and ANB both are good adsorbents compared to PP and APP.
\end{abstract}

D. P. Tiwari

Department of Chemical Engineering, DCRUST, Murthal,

Sonepat 131039, Haryana, India

e-mail: dptiwari3@gmail.com

S. K. Singh

Department of Civil Engineering, DTU, Delhi 110042, India

e-mail: sksinghdce@gmail.com

N. Sharma $(\bowtie)$

Bhagwan Mahavir Institute of Engineering and Technology,

Sonepat 131001, Haryana, India

e-mail: sharma.neetu80@gmail.com
Keywords $\mathrm{HCHO}$ treated potato peel (PP) - HCHO treated neem bark (NB) $\cdot \mathrm{H}_{2} \mathrm{SO}_{4}$ treated potato peel (APP) . $\mathrm{H}_{2} \mathrm{SO}_{4}$ treated neem bark (ANB) - Methylene blue (MB) . Percentage removal

\section{Introduction}

The demands of synthetic dyes have experienced significant growth in the past decades. Recent reports highlighted that more than 100,000 of various dyes are commercially available and annual worldwide production of dyestuffs surpassed to $7 \times 10^{5}$ metric tons (Pearce et al. 2003; Gong et al. 2005; Robinson et al. 2001). Extensive use of dyes and inefficiency in dying process leads to great loss of dyes to the main stream. The effluent from dying industry comprises moderate concentration $\left(10-200 \mathrm{mg} \mathrm{ml}^{-1}\right.$ ) of dyestuffs which contribute significant contamination of aquatic ecosystem (Neill et al. 1999). These stable compounds do not dissociate in environment and get accumulate in biota which further leave severe toxic and carcinogenic effects (Hu et al. 2006). Numerous physical, chemical and biological techniques are applied in past to attain maximum colour removal. Among them, adsorption technique is well accepted and considered to be an effective method for decreasing concentration of dissolved dyes in waste water (Reife et al. 1996). The adsorption process is fulfilled with little or no toxic pollutants and requires low initial capital and operating costs (Crini 2006).

Agricultural by-products have received significant interest in recent past by the researchers due to their abundance, non-hazardous nature and simple process of dye removal. Plentiful agricultural waste is used in recent past such as neem leaf powder (Bhattacharyya and Sharma 2004), tamarind fruit shell (Somasekhara Reddy 2006), 
jack fruit peel (Jayarajan et al. 2011), grapefruit peel (Abassi and Razzaghi 2009), rice husk (Abdelwahab et al. 2005), bark (McKay et al. 1999; Patil et al. 2011), sunflower seed husk (Ong et al. 2010) wheat straw (Hassanein Taha and Koumanova 2010) and saw dust (Shukla et al. 2002). These wastes have negligible economic value and often pose a disposal problem, so trying them as suitable adsorbent is the best alternative to utilize them.

In the present study, the removal efficiency of chemically treated potato peel and neem bark is observed on methylene blue (MB). The adsorption of MB by raw potato peel and neem bark has already been reported earlier as well by Öktem et al. 2012 and Srivastva and Rupainwar 2010 , respectively. The novelty of the present research is to examine the efficiency of these adsorbents by modifying them with chemicals. One part of both the adsorbents is treated with $\mathrm{HCHO}$, and other part is treated with $\mathrm{H}_{2} \mathrm{SO}_{4}$. The purpose of pre-treatment of raw adsorbent with formaldehyde is to remove the colour of raw adsorbents, which can interfere with the dye studied in order to achieve maximum colour removal with accuracy, whereas the acid treatment of both the adsorbents is done due to significant performance recorded by acid-treated adsorbents in past (Garg et al. 2003; Raghuvanshi et al. 2004; Parvathi et al. 2010). Adsorption isotherm and chemical kinetics are considered to find out the nature and mode of adsorption process. The present research will help in selecting the proficiently and economically suitable adsorbent for treatment of textile industry waste.

\section{Materials and methods}

Selection and preparation of sorbents

Two adsorbents potato peel and neem bark are selected as suitable adsorbents. Potato peel is obtained from mess of BMIET, while neem bark is collected from surrounding area of the same institute. Both the adsorbents are first washed with water and air dried in oven at $65^{\circ} \mathrm{C}$ for $24 \mathrm{~h}$. After drying, they are grinded and further treated with formaldehyde to restrict the integration of adsorbent's own colour with the dye tint.

Formaldehyde treatment of raw adsorbents

For removing the colour of raw adsorbents, the grinded potato peel is dipped in $6 \% \mathrm{HCHO}$ overnight and washed further with distil water until the decanted water became colourless and $\mathrm{pH}$ reached at neutral. The colour-abated potato peel is then dried in oven at $70{ }^{\circ} \mathrm{C}$ and further sieved to obtain the particles of $80-150 \mu \mathrm{m}$ mesh size. For removing the colour of neem bark, the grinded mixture is

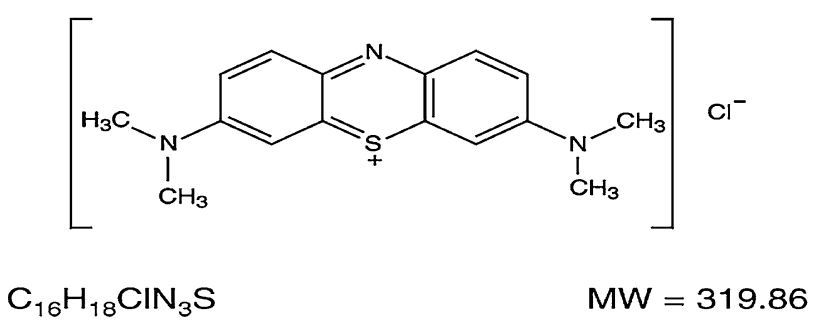

Fig. 1 Structure of methylene blue

dipped in a solution of $37 \% \mathrm{HCHO}$ and $0.2 \mathrm{~N} \mathrm{H}_{2} \mathrm{SO}_{4}$ overnight followed by soaking in $\mathrm{NaHCO}_{3}$ overnight to remove acid (Garg et al. 2003). After that, the same procedure of washing and drying is followed like potato peel. Finally the light brown coloured HCHO treated potato peel (PP) and dark brown coloured $\mathrm{HCHO}$ treated neem bark (NB) powders are obtained.

Acid treatment of the adsorbents

Both the adsorbents are treated with $\mathrm{H}_{2} \mathrm{SO}_{4}$ in 1:1 ratio and left overnight followed by washing with distil water many times until the $\mathrm{pH}$ reached at neutral. The black coloured powders of both the adsorbents are obtained after drying in oven at $105{ }^{\circ} \mathrm{C}$ and sieving through the mesh size of 80-150 $\mu \mathrm{m}$ mesh size.

The morphological and structural properties of all the four adsorbents are examined with the help of Hitachi, model S-3700, Scanning Electron Micrograph and Thermo Scientific Nicolet-380, FTIR.

Sorbet

The dye, $\mathrm{MB}$, chemical formula $=\mathrm{C}_{16} \mathrm{H}_{18} \mathrm{ClN}_{3} \mathrm{~S}$, $\mathrm{MW}=319.86, \lambda_{\max }=662$ is selected as sorbet. The structure of dye is given below in Fig. 1 .

Analytical procedure

Experiments are conducted by preparing 1,000 ppm of stock solution of MB. For determining the concentration of dye, Lambert-Beer's method is used. Analysis is done on double-beam Chemito UV-Visible Spectrophotometer having the wavelength range of 190-1,100 nm and bandwidth of $1.6 / 1.0 \mathrm{~nm}$. All the samples are examined on the recorded wavelength of $662 \mathrm{~nm}$. Standard concentrations of MB (1-10 ppm) are prepared to obtain the calibration curve, and graph factor is calculated to get accurate results with minimum error. A comparative study of removal of dye on all the four adsorbents is studied by considering various parameters like adsorbent dose, concentration of dye, $\mathrm{pH}$ of the solution and time. The experiments are performed in batches at room temperature by shaking 
$50 \mathrm{ml}$ of $100 \mathrm{ppm}$ (except the concentration effects) dye solution with $0.250 \mathrm{~g}$ (except the dose effects) of each adsorbent taken in $100 \mathrm{ml}$ of Erlenmeyer conical flask at the speed of $125 \mathrm{rpm}$.

Sorption of dye on various adsorbents is calculated by the mass balance equation given below where $q$ denotes the amount of dye adsorbed on the adsorbent (mg/g); $V$ denotes the volume of the solution (1); $m$ denotes the amount of adsorbent taken in $\mathrm{g}$; $C_{\mathrm{i}}$ and $C_{\mathrm{f}}$ denotes the dye concentration in $\mathrm{mg} / \mathrm{l}$ before and after adsorption, respectively.

$q=\frac{C_{\mathrm{i}}-C_{\mathrm{f}}}{m} \times V$

whereas percentage removal of dye is calculated by the given formula:

$\%$ removal $=\frac{C_{\mathrm{i}}-C_{\mathrm{f}}}{C_{\mathrm{i}}} \times 100$

Experimental validation

Three different isotherm models, Langmuir, Freundlich and Temkin, are fitted to analyse the isotherm data. The initial concentrations for analysing the suitable isotherm model followed by all the four adsorbents are selected as 20, 50, 100, 150 and 250 ppm.

Langmuir's and Freundlich's equations are commonly used to express the isotherms at constant temperature for waste water treatment operations (Eren and Acar 2006). The linear form of Langmuir's model supports the monolayer sorption hypothesis which occurs on the outer surface having infinite number of active sites. The empirical equation of Freundlich isotherm model is based on the sorption of dye over heterogeneous surface. Temkin's isotherm model usually applied to observe the chemisorptions behaviour of sorbent and sorbet. The linear form of Langmuir's, and empirical equation of Freundlich and Temkin's isotherm models are, respectively, explained by the following expressions:

$\frac{C_{\mathrm{e}}}{q_{\mathrm{e}}}=\frac{1}{Q_{0} b}+\frac{C_{\mathrm{e}}}{Q_{0}}$

$\log q_{\mathrm{e}}=\log K_{\mathrm{F}}+\frac{1}{n} \log C_{e}$

$q_{\mathrm{e}}=B \ln A+B \ln C_{\mathrm{e}}$

where in Langmuir's equation, $C_{\mathrm{e}}$ is the equilibrium concentration $(\mathrm{mg} / \mathrm{l}) ; q_{\mathrm{e}}$ is the amount of dye adsorbed $(\mathrm{mg} / \mathrm{g})$; $Q_{0}$ is the maximum dye per gram of adsorbent $(\mathrm{mg} / \mathrm{g})$; and $b$ is Langmuir's constant related to energy of adsorption (1/ $\mathrm{mg})$. In Freundlich's equation, $K_{\mathrm{F}}$ is the constant related to sorption capacity. $1 / n$ is an empirical parameter related to the sorption intensity of the adsorbent. $A$ is Temkin's constant representing sorbet-sorbent interactions, and $B$ is another constant related to the heat of adsorption.
One more essential feature of Langmuir's isotherm is determined which is a dimensionless constant separation factor (RL), expressed by the following equation given by Hall et al. (1966)

$\mathrm{RL}=1 /\left(1+b C_{0}\right)$

where $C_{0}$ is initial concentration of dye $(\mathrm{mg} / \mathrm{l})$, and $b$ is Langmuir's constant $(1 / \mathrm{mg})$. The value of RL defines the nature of adsorption as below

$\mathrm{RL}>1=$ unfavourable, $\mathrm{RL}=1$ linear, $\mathrm{RL}=0$ irreversible, $0<\mathrm{RL}>1=$ favourable

The experimental data are analysed to observe the appropriate kinetic model followed by adsorption process including mass transfer and chemical reactions. Pseudofirst-order and pseudo-second-order kinetic models are used to describe the kinetics of adsorption. The integrated form of Lagergren first-order kinetic model is represented by the equation given below:

$\log \left(q_{\mathrm{e}}-q_{\mathrm{t}}\right)=\log q_{\mathrm{e}}-\left(k_{1} / 2.303\right) t$

where $k_{1}$ is the rate constant of first-order adsorption (1/ $\min ) ; q_{\mathrm{e}}$ is the amount of dye adsorbed in $\mathrm{mg} / \mathrm{g}$ at equilibrium; and $q_{\mathrm{t}}$ is the amount of dye adsorbed in $\mathrm{mg} / \mathrm{g}$ at any time $t$. The linear form of pseudo-second-order kinetic model rate equation is expressed as:

$t / q_{\mathrm{t}}=1 / K_{2} q_{\mathrm{e}}^{2}+\left(1 / q_{\mathrm{e}}\right) t$

where $k_{2}$ is the rate constant of second-order adsorption (1/ min) depends on the sorption capacity of solid phase. The initial sorption rate, $h(\mathrm{mg} / \mathrm{g} \mathrm{min})$, is also calculated with the help of second-order kinetic model by the following expression:

$h=k_{2} q_{\mathrm{e}}^{2}$

\section{Results and discussion}

Morphological and structural study of adsorbents

All the four adsorbents obtained are analysed on SEM and FTIR to know about their morphological and structural properties. The SEM images of all the four adsorbents given in Fig. 2 show significant particle and pore size for the dye to be adsorb. From the images, it is evident that PP reflects the presence of smooth particles of size ranges up to $22-30 \mu \mathrm{m}$ while NB shows enough rough shape particles of average size from 8.38 to $10.6 \mu \mathrm{m}$. The SEM images confirmed that both the adsorbents have sufficient pore size and surface area for the sorption of dye.

The comparative chart of FTIR spectra of all the four adsorbents represents clearly that almost all the adsorbents show more or less similar characteristics adsorption spectra. From the chart, it is well depicted that $\%$ transmittance 

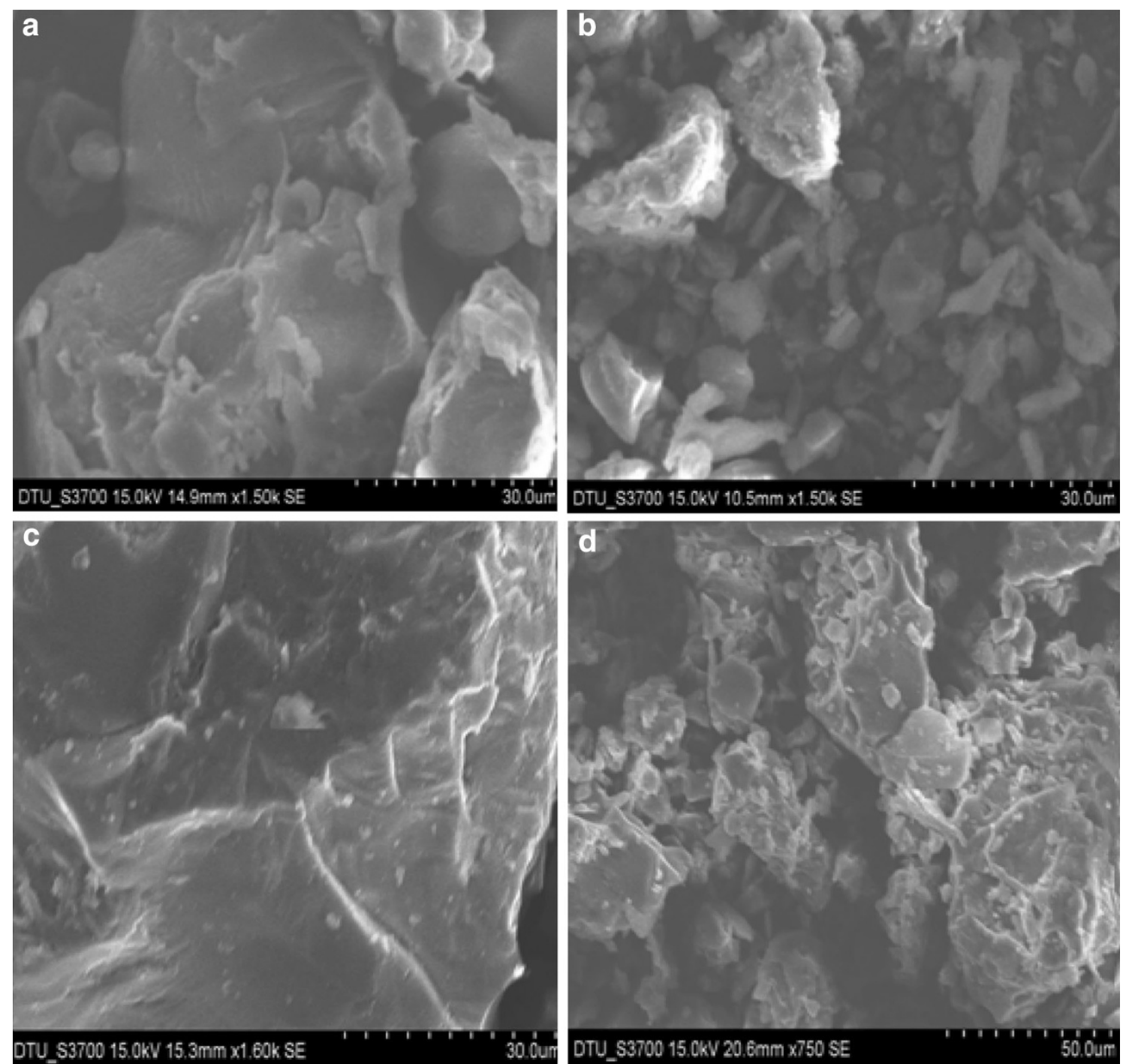

Fig. 2 SEM images of a PP, b NB, c APP, d ANB

Table 1 Different functional group recognized on all the four adsorbents through FTIR spectra

\begin{tabular}{|c|c|c|c|c|c|c|}
\hline Group & $\begin{array}{l}\text { Wavelength } \\
\text { range }\left(\mathrm{cm}^{-1}\right)\end{array}$ & PP & APP & NB & ANB & $\begin{array}{l}\text { MB-loaded } \\
\text { PP }\end{array}$ \\
\hline $\mathrm{O}-\mathrm{H}$ stretch & $\begin{array}{l}3,400-3,300 \\
\quad \text { (broad) }\end{array}$ & 3,403 & 3,429 & 3,413 & 3,402 & 3,441 \\
\hline C-H stretch & $2,950-2,800$ & 2,920 & - & 2,922 & - & 2,920 \\
\hline $\mathrm{C}=\mathrm{C}$ stretch & $1,690-1,630$ & 1,648 & & & & 1,652 \\
\hline $\begin{array}{l}\text { Carboxylic } \\
\text { group }\end{array}$ & $1,500-1,640$ & 1,517 & 1,629 & 1,618 & 1,616 & 1,517 \\
\hline Esters $(\mathrm{C}-\mathrm{O}-\mathrm{C})$ & $1,260-1,170$ & $\begin{array}{c}1,244 \\
1,158\end{array}$ & 1,170 & & 1,206 & 1,159 \\
\hline $\begin{array}{l}\text { Amines }(\mathrm{C}-\mathrm{N} \\
\text { stretch) }\end{array}$ & $1,200-1,025$ & 1,024 & & & & 1,024 \\
\hline $\begin{array}{l}\text { Sulphoxides } \\
\qquad(\mathrm{S}=\mathrm{O})\end{array}$ & $\sim 1,050$ & & 1,035 & 1,035 & & \\
\hline
\end{tabular}

is relatively greater in case of $\mathrm{NB}$ and $\mathrm{H}_{2} \mathrm{SO}_{4}$ treated neem bark (ANB) compared to $\mathrm{PP}$ and $\mathrm{H}_{2} \mathrm{SO}_{4}$ treated potato peel (APP). Table 1 elucidates various functional groups present on the surface of all the four adsorbents studied. These functional groups play major role in attracting the dye molecule from aqueous solution. It is well defined from the table that both potato peel and neem bark contain carboxylic group (hemicelluloses, pectin and lignin), phenolic (lignin, lipids and waxes), amines and sulphoxides group (Fig. 3).

\section{Effect of dose}

The effect of dose is studied by varying the amount of dose from 0.1 to $1.0 \mathrm{~g}$ of each adsorbent in $50 \mathrm{ml}$ of $100 \mathrm{ppm}$ of 
Fig. 3 Comparative chart showing FTIR spectra (starting from below-a APP, b methylene blue adsorbed on PP, c PP, d NB, e ANB)

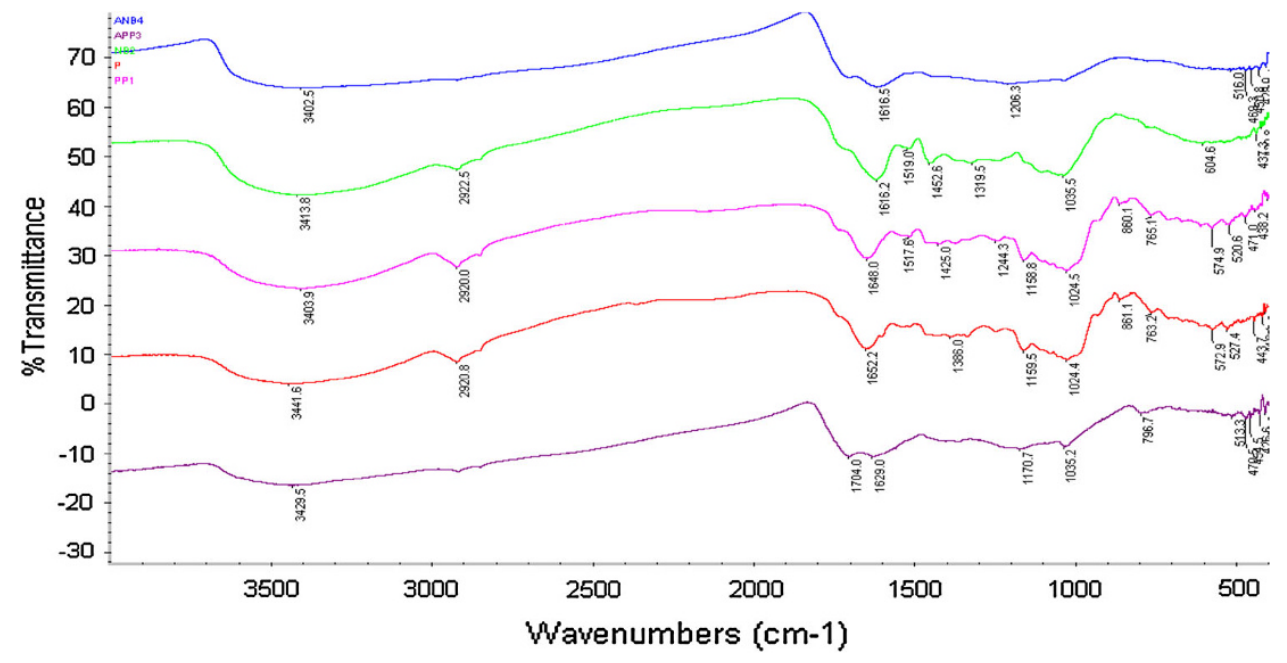

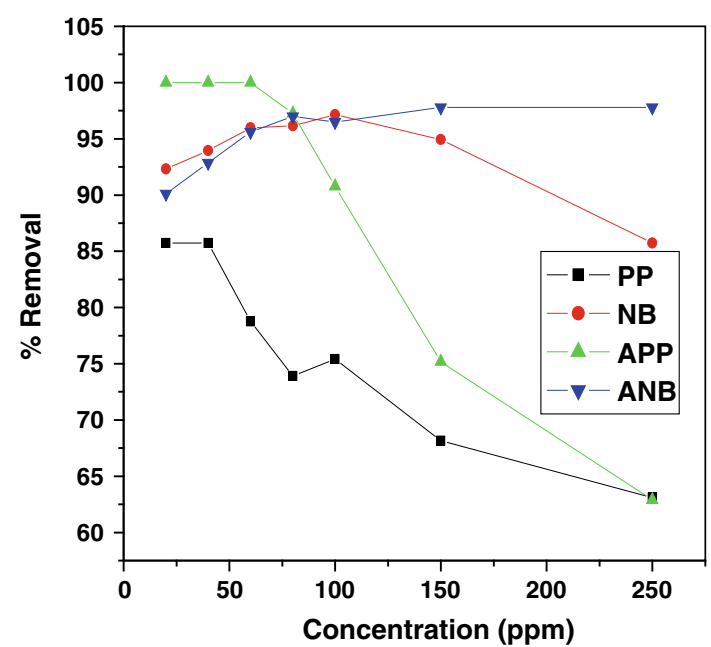

Fig. 5 Effect of initial dye concentration in removal of MB

a result of overcrowding of adsorbent particles (Namasivayam et al. 1998).

\section{Effect of concentration}

Effect of dye concentration is studied by keeping adsorbent dose constant at $0.250 \mathrm{~g}$ in $50 \mathrm{ml}$ of different concentration of dye varying from $20,50,60,80,100,150$ and 250 . Shaking is done for $30 \mathrm{~min}$ at room temperature. Decolourization is observed in first $15 \mathrm{~min}$ at lower concentrations. The \% removal of dye in case of PP, APP and NB decreases significantly from 85 to 63,100 to 62 and 92 to $85 \%$, whereas in ANB, the \% removal increases from 90 to $97 \%$ as depicted by the Fig. 5. The decrease in removal can be attributed to saturation of sorption sites on the adsorbent as the concentration of dye increases (Tan et al. 2010), while initial increase in removal up to $100 \mathrm{mg} / \mathrm{l}$ and further saturation of ANB may be due to sufficient sorbent accessibility to adhere with the sorbet. adsorption of dye is decreased in all cases after increasing
dose. This can be due to overlapping of adsorption sites as 
Effect of $\mathrm{pH}$

Adsorption of dye on all the four adsorbents showed significant removal with change in $\mathrm{pH}$. The optimum $\mathrm{pH}$ for removal of MB by $\mathrm{PP}, \mathrm{NB}, \mathrm{APP}$ and $\mathrm{ANB}$ is observed to be 8, 4, 12 and 2, respectively, as shown in Fig. 6. HCHO treated potato peel and APP showed significant variation in percent removal from 63 to 80 and 76 to $94 \%$, respectively, on changing $\mathrm{pH}$ from 2 to 14 , while NB and ANB showed less variation in per cent removal from 93 to 83 and 98 to $90 \%$, respectively, by varying the same $\mathrm{pH}$. HCHO treated neem bark and ANB showed good removal in acidic condition, while PP and APP showed significant removal in alkaline condition. Increase in negative charged ions on PP and APP favoured the adsorption of cationic dye in alkaline condition due to pectin present on surface of the two adsorbents (Flavio et al. 2008). Maximum removal of $\mathrm{MB}$ on $\mathrm{NB}$ and $\mathrm{ANB}$ in acidic medium may be due to the cellulosic compounds (carboxylic and phenolic groups) present on the adsorbent surface (Ferrero 2007).

\section{Adsorption isotherm}

The various isotherm (Langmuir, Freundlich and Temkin) parameters specified in Table 2 confirmed different type of

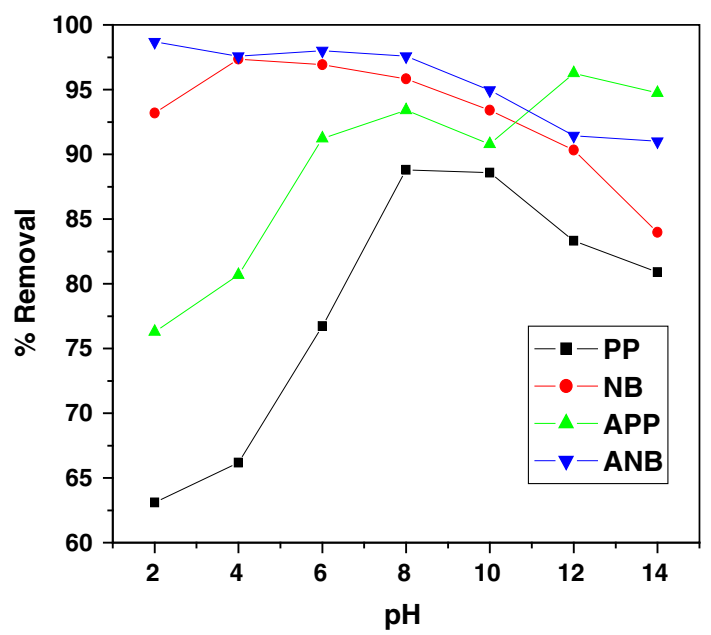

Fig. 6 Effect of $\mathrm{pH}$ in removal of $\mathrm{MB}$ sorption processes followed by the four adsorbents studied. From Table 2, it is clear that PP and APP responded good behaviour with all three types of isotherm models but Langmuir's isotherm fitted quite well with them which is also well explained by the good regression coefficient of 0.99 and 0.96, respectively. The Langmuir's model described the monolayer sorption nature of PP and APP. The maximum adsorption capacity of PP and APP obtained is 47.62 and $41.60 \mathrm{mg} / \mathrm{g}$, respectively, which are higher than $33.55 \mathrm{mg} / \mathrm{g}$ measured by Öktem et al. 2012 on raw potato peel.

It is well defined from Table 2 that Temkin's isotherm is best fitted with the adsorption behaviour of NB and ANB, showing good regression coefficient of 0.85 and 0.99 , respectively, compared to other two isotherms studied. Temkin's isotherm model reflects chemical adsorption mechanism between the dye and sorbent which takes into account the acquisition of the more energetic adsorption sites at first (Abdel-Ghani et al. 2007). The maximum adsorption capacity of neem bark powder for MB estimated by Srivastva and Rupainwar 2010 is $3.11 \times 10^{3} \mathrm{~mol}$ $\mathrm{g}^{-1}(994 \mathrm{mg} / \mathrm{g})$ which is higher than the NB efficiency of $90 \mathrm{mg} / \mathrm{g}$ but lower than the ANB efficiency of $1,000 \mathrm{mg} / \mathrm{g}$ measured.

In present study, the value of RL lies between 0.11 and 0.625 for PP and 0.03 and 0.31 for APP which are in the range of $0-1$, indicating that the adsorption process is favourable for both the adsorbents. The value of $n$ estimated is $>1$ for all the four adsorbents as depicted in Table 2. This represents that adsorption is favourable in nature.

\section{Chemical kinetics}

The kinetic plots of Eq. (8) and (9) are made at the initial concentration of $100 \mathrm{ppm}$ for all the four adsorbents. From Table 3, it is concluded that the second-order kinetic model fitted well with the observed data of all the four adsorbents. Similar results are reported for sorption of $\mathrm{MB}$ on potato peel (Öktem et al. 2012) and neem bark (Srivastva and Rupainwar 2010). The initial adsorption rate $h$ is higher in case of both NB and ANB as compared to PP and APP. The calculated values of $q_{\mathrm{e}}$ for all the four adsorbents from

Table 2 Comparison of adsorption isotherm of different adsorbents studied

\begin{tabular}{|c|c|c|c|c|c|c|c|c|c|}
\hline \multirow{2}{*}{$\begin{array}{l}\text { Isotherm models } \rightarrow \\
\text { Adsorbent } \downarrow\end{array}$} & \multicolumn{3}{|c|}{ Langmuir's isotherm model } & \multicolumn{3}{|c|}{ Freundlich's isotherm model } & \multicolumn{3}{|c|}{ Temkin's isotherm model } \\
\hline & $K_{\mathrm{L}}(\mathrm{b})$ & $Q_{0}$ & $R^{2}$ & $K_{\mathrm{F}}$ & $N$ & $R^{2}$ & $B$ & $A$ & $R^{2}$ \\
\hline PP & 0.03 & 47.62 & 0.99 & 1.87 & 1.46 & 0.95 & 8.89 & 0.39 & 0.98 \\
\hline NB & 0.03 & 90.91 & 0.21 & 3.63 & 1.35 & 0.56 & 0.06 & 43,477 & 0.85 \\
\hline APP & 0.107 & 41.60 & 0.96 & 7.46 & 2.80 & 0.64 & 0.116 & 0.056 & 0.86 \\
\hline ANB & 0.006 & $1,000.0$ & 0.005 & 6.51 & 1.10 & 0.84 & 19.60 & 1.35 & 0.99 \\
\hline
\end{tabular}


Table 3 Kinetics of pseudo-first and pseudo-second order of different adsorbents studied

\begin{tabular}{|c|c|c|c|c|c|c|c|c|}
\hline \multirow[t]{2}{*}{ Adsorbents } & \multicolumn{3}{|c|}{ Pseudo-first order } & \multicolumn{4}{|c|}{ Pseudo-second order } & \multirow[t]{2}{*}{$\overline{q_{\mathrm{e}}(\exp )}$} \\
\hline & $q_{\mathrm{e}}(\mathrm{cal})$ & $K_{1}$ & $R^{2}$ & $q_{\mathrm{e}}(\mathrm{cal})$ & $K_{2}$ & $R^{2}$ & $H$ & \\
\hline PP & 1.5 & 0.009 & 0.14 & 17.5 & 0.29 & 0.99 & 2.7 & 17.6 \\
\hline NB & 0.71 & 0.016 & 0.29 & 19.2 & 0.016 & 0.99 & 22.1 & 19.2 \\
\hline APP & 5.04 & 0.034 & 0.70 & 20.0 & 0.015 & 0.99 & 0.4 & 20.0 \\
\hline ANB & 0.52 & 0.006 & 0.10 & 19.6 & 2.60 & 0.99 & 42.2 & 19.6 \\
\hline
\end{tabular}

second-order kinetic equation are found to be agreed well with the experimental values of $q_{\mathrm{e}}$.

\section{Conclusion}

The efficiency of four adsorbents PP, APP, NB and ANB for removing $\mathrm{MB}$ is evaluated by varying dose, $\mathrm{pH}$ and concentration. On varying dose, the \% removal of PP, NB and APP also increases from 75 to 93,92 to 96 and 75 to $100 \%$, respectively, due to availability of more surface area on the adsorbents, while the \% removal of ANB decreases with increase in dose due to overcrowding of the adsorbent which in turn decreases the efficiency. On changing concentration, the \% removal of dye in case of PP and APP decreases significantly from 85 to 63 and 100 to $62 \%$ while little decrease is observed in case of NB and ANB from 92 to 85 and 90 to $97 \%$, respectively. The decrease in removal may be attributed due to saturation of sorption sites on the adsorbent as the concentration of dye increases (Tan et al. 2010). The optimum $\mathrm{pH}$ for removal of MB on PP, NB, APP and ANB are observed to be 8,4 , 12 and 2 , respectively.

The maximum dye adsorption capacity, $Q_{0}$ observed for $\mathrm{NB}$ and $\mathrm{ANB}$, is 90.91 and $1,000 \mathrm{mg} / \mathrm{g}$, respectively, which is $>76.9 \mathrm{mg} / \mathrm{g}$ for the removal of $\mathrm{MB}$ on hazelnut shell as reported by Ferrero 2007. The $Q_{0}$ estimated for NB in present study is lower than the value $3.11 \times 10^{3} \mathrm{~mol} / \mathrm{g}$ estimated by Srivastva and Rupainwar 2010, but the later reported is less than the ANB sorption capacity of present study. The $Q_{0}$ observed for PP and APP is 47.62 and $41.6 \mathrm{mg} / \mathrm{g}$, respectively, which are higher than the efficiency measured for MB on cherry saw dust, Oak saw dust and pitch pine saw dust reported by Ferrero 2007.

The physical adsorption behaviour of PP and APP is well supported by Langmuir's adsorption isotherm. HCHO treated neem bark and ANB followed chemisorptions nature which is acknowledged by the good correlation of Temkin's isotherm. SEM and comparative chart of FTIR spectra of all the four adsorbents are in favour of the results obtained. The second-order kinetic model fitted well with the observed data of all the four adsorbents.
From the present research, it is estimated that NB and ANB are better adsorbent than PP and APP but neem bark performed efficiently in acid treated nature whereas potato peel worked better in $\mathrm{HCHO}$ treated form.

Acknowledgments The corresponding author extends sincere thanks to SSN College, D.U, and D.T.U. Delhi for performing the experimental work. The support of the staff of DCRUST, Murthal remained greatly admirable throughout the work.

Open Access This article is distributed under the terms of the Creative Commons Attribution License which permits any use, distribution, and reproduction in any medium, provided the original author(s) and the source are credited.

\section{References}

Abassi MN, Razzaghi Asl (2009) Removal of hazardous reactive blue 19 dye from aqueous solution by agricultural waste. J Iran Chem Res 2:221-230

Abdel-Ghani NT, Hefny M, El-Chaghaby GAF (2007) Removal of lead from aqueous solution using low cost abundantly available adsorbents. Int J Environ Sci Technol 4(1):67-73

Abdelwahab O, Ahmed N, Amany ES, Khaled A (2005) Use of rice husk for adsorption of direct dyes from aqueous solution: a case study of Direct F. Scarlet. Egypt J Aquat Res 31(1):1110-0354

Araujo MM, Teixeira JA (1997) Trivalent chromium sorption on alginate beads. Int J Bio Deterior Biodegrad 40:63-74

Bhattacharyya KG, Sharma A (2004) Azadirachta indica leaf powder as an effective biosorbent for dyes: a case study with aqueous Congo red solutions. J Environ Manag 71:217-229

Crini G (2006) Non-conventional low-cost adsorbents for dye removal: a review. Bioresour Technol 97:1061-1085

Eren Z, Acar FN (2006) Adsorption of Reactive Black 5 from an aqueous solution: equilibrium and kinetic studies. Desalination 194:1-10

Ferrero F (2007) Dye removal by low cost adsorbents: hazelnut shell in comparison with wood saw dust. J Hazard Mater 142:144-152

Flavio AP, Mazzocato AC, Gushikem Y (2008) Removal of methylene blue dye from aqueous solution by adsorption using yellow passion fruit peel as adsorbent. Bioresour Technol 99:3162-3165

Garg VK, Gupta R, Yadav AB, Kumar R (2003) Dye removal from aqueous solution by adsorption on treated saw dust. Bioresour Technol 89:121-124

Gong R, Li M, Yang C, Sun Y, Chen J (2005) Removal of cationic dyes from aqueous solution by adsorption on peanut hull. J Hazard Mater B121:247-250

Hall KL, Eagleton LC, Acrivos A, Vermeulen T (1966) Pore and solid-diffusion kinetics in fixed bed adsorption under constant pattern conditions. Ind Eng Chem Fundam 5:212-223

Hassanein Taha F, Koumanova B (2010) Evaluation of adsorption potential of the agricultural waste, wheat straw for basic yellow 21. J Univ Chem Technol Metall 45(4):407-414

Hu ZG, Zhang J, Chan WL, Szeto YS (2006) The sorption of acid dye onto chitosan nano particles. Polymer 47:5838-5842

Jayarajan M, Arunachalam R, Annadura G (2011) Agricultural wastes of jackfruit peels nano-porous adsorbent for removal of rhodamine dye. Asian J Appl Sci 4(3):263-270

McKay G, Porter JF, Prasad GR (1999) The removal of dye colours from aqueous solutions by adsorption on low cost materials. Water Air Soil Pollut 114:423-438

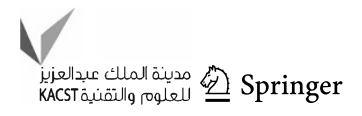


Namasivayam C, Muniasamy N, Gayathri K, Rani M, Ranganathan K (1996) Removal of dyes from aqueous solutions by cellulose waste orange peel. Bioresour Technol 57:37-43

Namasivayam C, Prabha D, Kumutha M (1998) Removal of dyes by adsorption onto agricultural solid waste. Bioresour Technol 64:77-79

Neill CO', Hawkes FR, Hawkes DL, Lourenco N, Pinheiro HM, Delee W (1999) Colour in the textile effluents-sources, measurements discharge consents and simulation: a review. J Chem Technol Biotechnol 74(11):1009-1018

Öktem YA, Soylu SGP, Aytan N (2012) The adsorption of methylene blue from aqueous solution by using waste potato peels; equilibrium and kinetic studies. J Sci Ind Res 71:817-821

Ong ST, Keng P, Lee SL, Leong MH, Hung YT (2010) Equilibrium studies for the removal of basic dye by sunflower seed husk (Helianthus annuus). Int J Phys Sci 5(8):1270-1276

Parvathi C, Maruthvanan T, Sivamani S, Prakash C, Koushik CV (2010) Role of tapioca peel activated carbon (TPAC) in decolourisation of red brown $\mathrm{C} 4 \mathrm{R}$ reactive dye. Indian $\mathrm{J}$ Sci Tech 3(3):290-292

Patil S, Renukdas S, Patil N (2011) Removal of methylene blue, a basic dye from aqueous solution by adsorption using teak tree (Tectona grandis) bark powder. Int J Environ Sci 1(5):711-725

Pearce CL, Lloyd JL, Guthrie JT (2003) The removal of colour from textile waste water using whole bacterial cells: a review. Dye Pigment 58(3):179-196
Raghuvanshi SP, Singh R, Kaushik CP (2004) kinetics study of methylene blue dye Bioadsorption on bagasse. Appl Ecol Environ Res 2(2):35-43

Reife A, Freeman HS (1996) Environmental chemistry of dyes and pigments. Wiley, New York

Robinson T, Chandran B, Nigam P (2001) Studies on the production of enzymes by white-rot fungi for the decolourisation of textile dye. Enzym Microbiol Technol 29:575-579

Shukla A, Zhang YH, Dubey P, Margrave JL, Shukla SS (2002) The role of saw dust in removal of unwanted materials from water. J Hazard Mater B 95:137-152

Somasekhara Reddy MC (2006) Removal of direct dye from aqueous solution with an adsorbent made from tamarind fruit shell, an agricultural solid waste. J Sci Ind Res 65:443-446

Srivastva R, Rupainwar DC (2010) Liquid phase adsorption of indigo carmine and methylene blue on neem bark. Desalin Water Treat 24:74-84

Tan LS, Jain K, Rozaini CA (2010) Adsorption of textile dye from aqueous solution on pre-treated mangrove bark, an agricultural waste: equilibrium and kinetics studies. J Appl Sci Environ Sanit 5(3):283-294 